\title{
Vigilar y programar: \\ sobre la dimensión política del software
}

\author{
RUBÉN JORDÁN \\ Pontificia Universidad Católica del Perú
}

Resumen:

El presente artículo explora el carácter farmacológico de la tecnología a partir del caso del software libre de navegación anónima por internet y su potencial político. Se defiende la tesis de que el software, que es la base del sistema de vigilancia y control psicopolítico neoliberal descrito por Byung-Chul Han, puede ser al mismo tiempo, cuando se implementa en programas de código abierto que camuflan nuestra huella digital, una herramienta para la resistencia y emancipación. Esto se debe a que dicha implementación ataca los principios fundamentales de la lógica de dominación dataísta: la transparencia y la predictibilidad.

Palabras clave:

software, virtualidad, resistencia, política, neoliberalismo

\begin{abstract}
:
This article explores the pharmacological character of technology in the light of the anonymous internet browsing free software case and its political potential. It is contended that software, which is at the foundation of the neoliberal surveillance and psychopolitical control system depicted by Byung-Chul Han, may be at the same time, when implemented in open-source programs that hide our digital fingerprint, a tool for resistance and emancipation. This is due to the fact that such implementation attacks the fundamental principles of the dataist domination logic: transparency and predictability.
\end{abstract}

Key words:

software, virtuality, resistance, politics, neoliberalism 
"La libertad es esclavitud", era la frase escrita en la fachada del ministerio de la verdad de la sociedad distópica que Orwell se imaginó en 1984 (2000,34). Varias décadas después, esta consigna se aplica perfectamente a la sociedad postindustrial. Hoy, a diferencia de lo que ocurría en los totalitarismos violentos del pasado, el hombre del capitalismo financiero no necesita ser coaccionado físicamente, sino que él mismo contribuye voluntariamente a su propia opresión, de modos que, irónicamente, incrementan su percepción subjetiva de libertad. Byung-Chul Han asocia estos nuevos mecanismos de control al dominio de la psique del ser humano, y no de su cuerpo. En este contexto, es inevitable notar que un elemento constitutivo de esta lógica sutil de sujeción es el software. Su naturaleza incorpórea, aunada a su potencia técnica, hacen de esta entidad informática un gran aliado del neoliberalismo en el proceso de seducción y captura de la mente humana; ya sea haciéndonos creer que acelera y extiende la comunicación en nombre de la productividad, o construyendo representaciones precisas de nosotros mismos en base a nuestros datos, el software es el instrumento más eficiente de la suave y autoinfligida opresión de nuestros días.

Sin embargo, como toda tecnología, el software es farmacológico, admite paradojas y contradicciones, por lo que en cualquiera de sus dimensiones cabe esperar potenciales reconfiguraciones de los mismos desafíos que plantea. En el presente ensayo se justificará la tesis de que el software, que está en el núcleo del esquema de control psicopolítico neoliberal, puede, al mismo tiempo, ser una herramienta de emancipación y resistencia. Concretamente, se analizará el caso del software libre que permite la navegación anónima por la red, el cual, además de ser hostil al carácter individualista del neoliberalismo, posibilita a los usuarios atacar los principios fundamentales del dataísmo, a saber, la transparencia y la predictibilidad. Se mostrará, pues, que, dependiendo del uso que se le dé, la misma tecnología que hace de la libertad esclavitud, puede hacerla verdadera libertad.

En primer lugar, una constatación que da indicios del potencial político de nuestro objeto de estudio: todo software, en tanto creación colectiva y textual, tiene una naturaleza intersubjetiva y cooperativa. En palabras de Roncoroni, "El software, precisamente por su naturaleza lingüística, es en realidad, más una forma de comunicación que una máquina propiamente 
dicha" $(2012,51)$. Esto es válido tanto para el software servil a la psicopolítica, ese que es propiedad de grandes corporaciones y que recopila incesantemente la información que voluntaria e involuntariamente le proporcionamos; como también para el llamado software libre, que es gratuito y cuyo código es accesible y editable a cualquier usuario, lo cual permite, a diferencia del software propietario, exponer la dimensión textual normalmente oculta de los programas informáticos. En este caso la intersubjetividad y la colaboración son cuantitativa y cualitativamente superiores; lo primero porque su alcance es más extenso y democrático, lo segundo porque, al no estar subordinada a la lógica de la propiedad y el lucro, es una colaboración que va más allá de la mera instrumentalidad técnica; por ello admite mayores posibilidades creativas, una mayor espontaneidad, y una comunicación descentralizada, menos jerárquica, reformulando tanto la dialéctica entre programadores, como entre el usuario y el software. El usuario de software libre, ya sea alterando el código o simplemente ejecutándolo, deja de ser consumidor de un producto que se vende, para convertirse en parte voluntaria de un proyecto colectivo dinámico y sinérgico; se ve inmerso, pues, en un entorno favorable a nuevas formas de participación política.

El carácter comunitario del software libre es hostil al neoliberalismo, en tanto representa una amenaza al espíritu individualista que subyace a este último. El sujeto neoliberal, al igual que su predecesor liberal ilustrado, es un sujeto cerrado sobre sí mismo, no solo incapaz de cooperar o consensuar acciones políticas relativas a tal cosa como un bien común, sino también de establecer vínculos sociales no instrumentales. Han lo llama "sujeto de rendimiento" y afirma que su aislamiento obedece a la subordinación de sus interacciones a la lógica de la productividad y la competitividad (2014, 7-8); esto es justamente lo que el software libre permite superar. Al no tener propietarios ni una finalidad comercial, este objeto digital realiza, en cierto sentido, dos utopías; a saber, la colectivización de los medios de producción económica que planteó Marx, y la "inteligencia colectiva" de Levy, que no es otra cosa que un ideal de pensamiento grupal o una "inteligencia totalmente distribuida que se mejora y sinergiza continuamente en tiempo real" $(1998,122)$. 
En segundo lugar, el ámbito concreto de aplicación del software libre en el que este potencial político se materializa más claramente es el de los programas que proporcionan anonimato en la navegación por internet, pues al combatir directamente la transparencia y la predictibilidad, que son principios fundamentales del dataísmo psicopolítico, libera, al menos parcialmente, a nuestra psique del control neoliberal. Como es de público conocimiento, el software neoliberal sirve a los fines de la vigilancia, el rastreo y el monitoreo de los usuarios, en tanto recopila permanentemente, a través de la red, una infinidad de datos sobre ellos. Estos van desde los aparentemente más inofensivos, como sus nombres, edades o estaturas, pasando por los que conciernen a información más personal, como la dirección IP, un número que identifica unívocamente cada punto de conexión a internet y que codifica la ubicación geográfica del usuario, hasta llegar a los más peligrosos, que son los que intentan captar las profundidades de nuestra psique y de los que muchas veces ni siquiera somos conscientes. Hoy, algoritmos de inteligencia artificial pueden inferir, con un alto grado de precisión, nuestro estado de ánimo en base a patrones de tipeo o la velocidad con la que desplazamos el dedo en el celular. Zuboff entiende este "capitalismo de la vigilancia" como un "secuestro de la experiencia humana" que acapara nuestro "excedente conductual", esto es, los datos que no sirven a la mejora de los servicios de software, sino al incremento de la rentabilidad de las compañías $(2019,128)$. Así, además de convertirnos en objetos transparentes, representables y medibles en base a la acumulación de nuestra información, la aplicación de algoritmos probabilísticos a estas grandes bases de datos nos convierte en objetos altamente predecibles y por ende inofensivos. Aunque a veces los datos se entregan voluntaria y conscientemente, como cuando usamos las redes sociales, y a veces se entregan inconscientemente, como cuando nuestro historial de navegación queda registrado sin que nosotros lo autoricemos; en cualquier caso, como bien señala Han, nada de esto ocurre por coacción, sino por seducción. La "dictadura de la transparencia" (Han 2014, 11-14) nos arranca, sutil y agradablemente, lo más íntimo de nuestra subjetividad y hace de nuestros estados mentales una simple mercancía, sentando las bases de un "totalitarismo digital" (Han 2014, 47), que subsume al ser humano al ámbito de las cosas. 
En este contexto, aplicaciones de software libre que buscan evitar generar una huella digital en internet, tales como el navegador Tor (ver imagen 1) o el servicio de correo electrónico temporal Guerrillamail (ver imagen 2), por ejemplo; muestran que es posible escapar a la lógica dataísta psicopolítica. El primero oculta, entre otros datos, la dirección IP de los usuarios para que ni sus proveedores de internet ni los dueños de las páginas que visitan en la red los puedan identificar, el segundo brinda la posibilidad de enviar correos electrónicos desde una dirección electrónica anónima que desaparece al cabo de una hora de usarse. Todo esto se hace ofreciendo

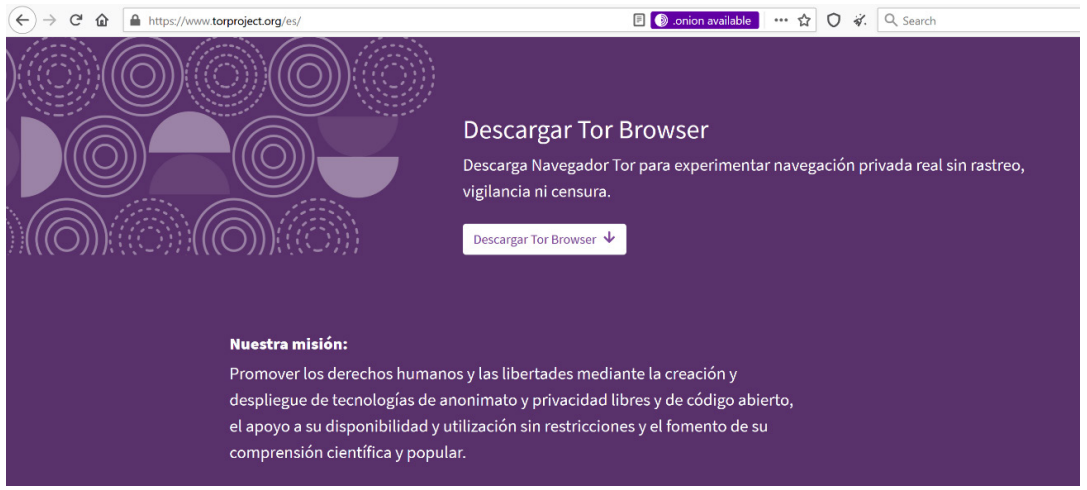

Imagen 1: Página web del navegador Tor, en la que se enuncia su propósito político.

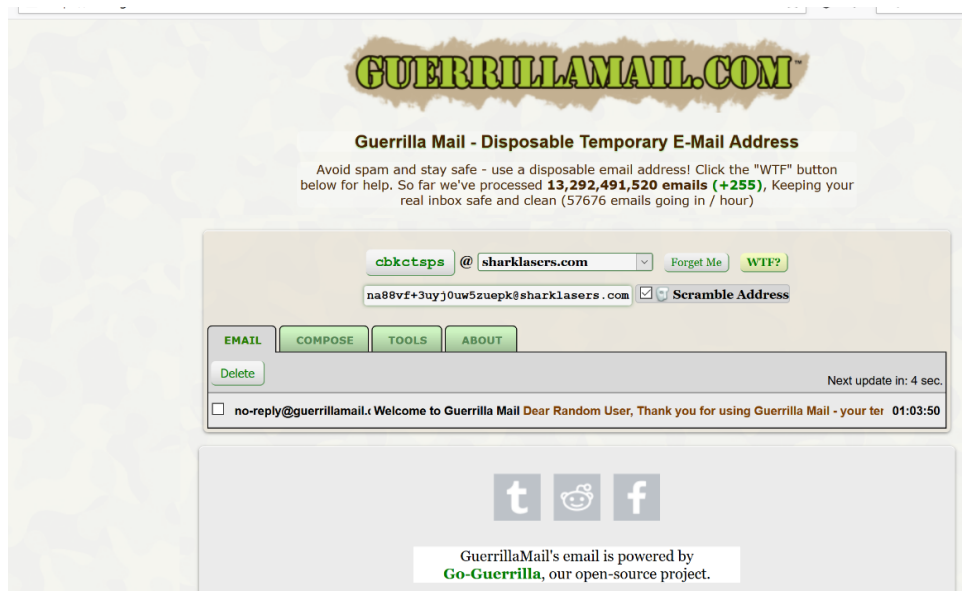

Imagen 2: Interfaz de Guerrillamail. Es incluso más amigable al usuario que el correo de Google. 
públicamente tanto el código, para su eventual modificación, como un soporte comunitario que tiene por objeto facilitar la relación usuario-interfaz (ver imagen 3).

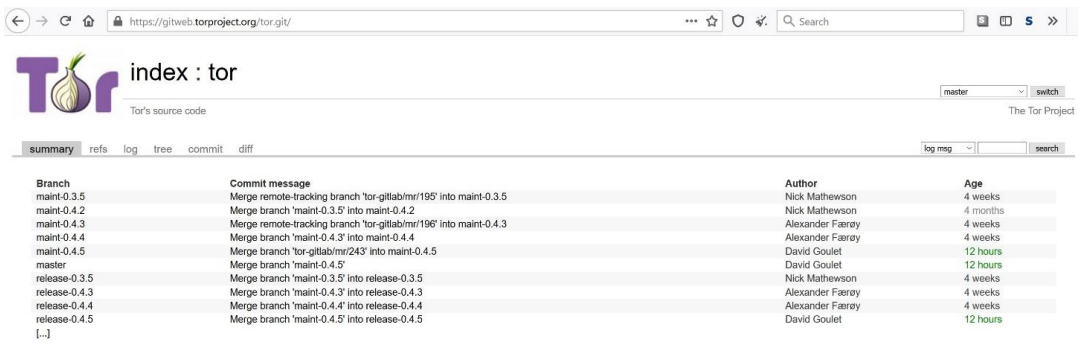

Imagen 3: Registro de cambios públicos en el código de Tor. Estos también pueden ser anónimos y de uso personal.

Estas implementaciones, como muchas otras, permiten una resistencia en dos niveles. En un primer nivel, básico y pasivo, se interrumpe la recopilación de datos por parte del software neoliberal, atacando así el principio de transparencia y privando al dataísmo de su materia prima. El ser humano, sin renunciar al uso del software, deja de ser, al menos parcialmente, un órgano reproductor de los datos, con lo que reivindica de nuevo su multidimensionalidad y continuidad, y recuerda por un momento que la riqueza y complejidad de su existencia, tanto corporal como fundamentalmente mental, es irreductible a la fría y discreta cuantificación numérica. Este software actúa como un velo que nos cubre en tanto positum y nos devuelve a la negatividad imposible de representar del anonimato. Al hacer esto, nos reconcilia con la dimensión misteriosa y ausente de la experiencia humana, que se oculta en lo más íntimo de nuestra psique y que es habitada por emociones en potencia, refractarias a la inteligibilidad, ya sea esta mediada por imágenes, conceptos, palabras o, cuanto más, datos. Paradójicamente, el software, que es un producto de la razón, corrige el error categorial de pretender captar racionalmente vivencias intuitivas, únicas e inefables. Error inaugurado por la modernidad filosófica y su culto a la ciencia positiva, pero motivado por el sempiterno, ingenuo $y$, sobre todo, opresivo deseo de controlar la incertidumbre inevitable de la vida humana $y$, en última instancia, negar la muerte; es decir, el deseo de deshumanizarnos. Así pues, el software libre de anonimato da un primer paso para resignificar la libertad, y rescatarla de su tergiversación neoliberal. 
En un segundo nivel, el hecho de que el software de anonimato opere en base a la criptografía, socava la predictibilidad dataísta y abre la puerta a una resistencia más sofisticada y activa. Para ocultar los datos, estos programas no solo se abstienen de entregarlos a las aplicaciones en red (lo cual sería equivalente a no usar software en absoluto), sino que, empleando algoritmos de encriptamiento, modifican estos datos hasta hacerlos irreconocibles, para solo entonces proporcionarlos a la red; en otras palabras, no solo se ocultan los datos verdaderos del usuario, sino que se alimenta a los algoritmos psicopolíticos con datos falsos (ver imagen 4). Como consecuencia, las bases de datos sobre las que operan varias formas de inteligencia artificial como el Data Mining o el Machine Learning se ven distorsionadas, lo cual afecta el nivel de confianza y la eficacia de sus predicciones. Así, el sujeto puede escapar a la uniformización y recuperar su autonomía. Al minar la precisión estadística del software psicopolítico, el ser humano, en particular su psique, se reclama como impredecible e inaprehensible, redime la espontaneidad inherente a su experiencia vital y, por tanto, se abre la posibilidad a una nueva y genuina libertad, en la que se puede colocar la potencia técnica del software al servicio del hombre, y no al revés. Además, este segundo nivel de resistencia resalta la importancia del carácter comunitario del proyecto de emancipación y demuestra que

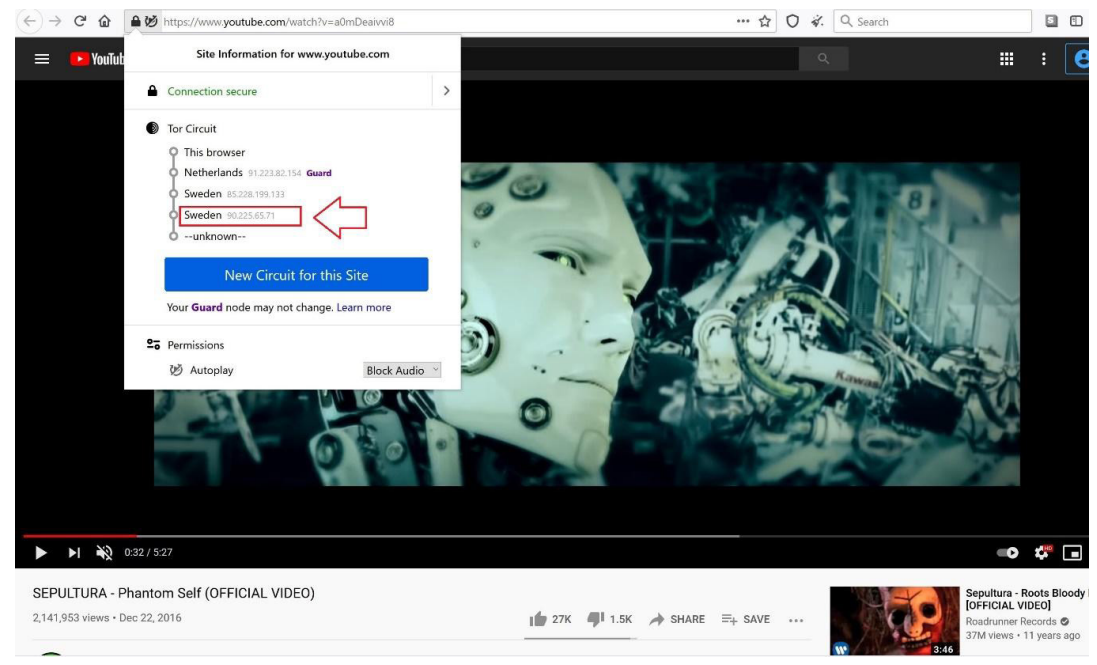

Imagen 4: Aquí, YouTube cree que se ve el video desde Suecia. Esto distorsiona sus bases de datos y afecta la precisión estadística de sus algoritmos. 
la cooperación política es posible y, de hecho, fundamental al nivel de usuario, pues cuanto más masivo y democrático sea el uso del software de anonimato, mayor será la cantidad y proporción de datos falsos que reciba el aparato de vigilancia y por tanto sus posibilidades de hacer inferencias certeras sobre nuestra psicología inconsciente y nuestra conducta futura serán tanto menores. El uso comunitario de este tipo de software nos despierta de la ilusión de creer que la aplicación de métodos matemáticos a un conjunto de datos alfanuméricos puede decirnos algo sobre las profundidades de nuestra interioridad, o ponerle límites instrumentales a la dignidad humana. Así pues, es claro que el mismo elemento que sirve de base técnica para el esquema psicopolítico neoliberal, nos permite, en algunas de sus metamorfosis, rebelarnos y escapar a esta lógica de dominación.

Cabe mencionar que el potencial emancipatorio del software libre está constreñido por su alcance técnico y que ciertamente el "panóptico digital" (Han 2014, 34) cuenta con mecanismos, también técnicos, para contraatacar (ver imagen 5); por ejemplo, la llamada "verificación en dos pasos" que implementan muchas redes sociales populares y que consiste en exigir al usuario no solo un nombre y una contraseña para identificarse, sino también un número telefónico, es una forma de redimensionar la vigilancia

$\leftarrow \rightarrow$ C $\rightarrow$ https://www.google.com/sorry/index?continue=https://www.youtube.com/v

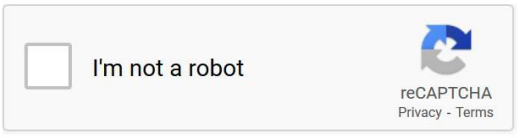

\footnotetext{
About this page

Our systems have detected unusual traffic from your computer network. This page checks to see if it's really you sending the requests, and not a robot. Why did this happen?

IP address: 135.148 .32 .173

Time: 2021-03-03T12:33:34Z

URL: https://www.youtube.com/watch?v=a0mDeaivvi8\& pbjreload $=101$
}

Imagen 5: A veces, el software neoliberal contraataca. Aquí, YouTube impide ver el video anterior. Esto se resuelve reiniciando el programa. La IP que tienen sigue siendo falsa. 
y obstaculizar la resistencia incorporando elementos analógicos aparentemente soslayados en el ámbito digital. Pues bien, esta constatación no hace más que recordarnos que el estatuto ontológico de la virtualidad es esencialmente el mismo que la realidad, en otras palabras, que la virtualidad es la realidad misma, porque se reproducen en el plano del software las características propias de cualquier relación poder-resistencia que se quiera examinar empíricamente a lo largo de la historia. La premisa básica de todo esfuerzo de resistencia política es la existencia de un poder omniabarcante y la consecuente desigualdad y asimetría en las posibilidades de operación, pero esto no es óbice para que se configure una dinámica de acción y reacción entre el poder y la resistencia. Tal dinámica es exagerada en la virtualidad digital, pues el carácter ubicuo, descentralizado e intersubjetivo del software libre hace posible concertar inmediatamente acciones de respuesta a las reacciones del poder psicopolítico, ya sea modificando el código, creando herramientas complementarias o alterando las pautas de uso. En el ejemplo anterior, una acción de respuesta inmediata fue la creación de software que simula anónima y temporalmente un número telefónico, usando la tecnología VolP (Voice over IP).

Se objetará seguramente que esta propuesta de uso político del software no es tan democrática como parece, pues las posibilidades de participación en ella dependen de una variable epistémica más bien excluyente, a saber, que hace falta un determinado nivel de conocimiento teórico y técnico de la estructura del software. Creo que conviene relativizar esta objeción, pues, como se ha mostrado, la esencia insurrecta del software libre radica no solo en la manipulación del código, sino fundamentalmente en su relación con el usuario, y no simplemente en el uso directo, que por lo demás no exige mayores habilidades que las que exige el software psicopolítico. Esta esencia insurrecta opera en un segundo nivel de intencionalidad; es decir, independientemente de saber usar o programar el software, la condición epistémica que posibilita la resistencia digital es saber para qué es que se usa o programa este software, lo cual implica tener la conciencia del carácter engañoso de la sensación de libertad que ofrece el neoliberalismo, estar al tanto de los métodos que el dataísmo usa para favorecer la transparencia y predictibilidad, y tener la voluntad de oponerse tanto pasiva como activamente a ellos. Esto significa que, más que conocer las minucias 
técnicas, internas o externas, del software, hace falta querer dejar de contribuir a la propia opresión y entender que lo realmente valioso de la vida humana no puede ser representado por datos, y que intentar hacer esto solo nos empobrece existencialmente. En este nivel se incluye, por tanto, la confianza en el uso del software de resistencia, el grado de convicción de que estos programas hacen lo que dicen que hacen, lo cual podría lograrse, por supuesto, leyendo el código; pero no hace falta, pues se alcanza principalmente en base al sentido de pertenencia a un ideal político y a una comunidad, formada mayoritariamente por otros usuarios, para lo cual no es indispensable el conocimiento técnico. En el caso del software libre de anonimato, la autoridad epistémica no es de una corporación, ni siquiera de los programadores, sino de la comunidad de usuarios.

Aunque, por supuesto, nada de esto va en desmedro del valor epistémico-político que el conocimiento de los lenguajes de programación supone por sí mismo. En particular, la posibilidad de acceder y entender el texto que constituye el software relativiza la propuesta de Stiegler, según la cual nuestra relación con la digitalidad está "proletarianizada"; ello significaría que la capacidad de procesamiento de cualquier programa sobrepasa los límites de nuestro saber teórico (Stiegler 2016, 195). Creo que este análisis es muy pertinente en lo que atañe al software propietario neoliberal, que con precisa ironía Stiegler identifica con los "cuatro jinetes del apocalipsis (Google, Apple, Facebook y Amazon)", pero no al software libre, porque este último, a diferencia del primero, no es una caja negra, pues sus propósitos y los mecanismos que emplea para conseguirlos están expuestos. El software neoliberal quiere transparentar la psique y ocultar el conocimiento, el software libre busca transparentar el conocimiento, pero ocultar la psique. $\mathrm{Si}$ el código es visible e inteligible, su lector puede tomar conciencia de los límites que la sintaxis y semántica de cualquier lenguaje de programación imponen a las capacidades de procesamiento y representación del software. De la misma forma que el lenguaje humano tiene solo un ínfimo poder de aprehender la cambiante realidad exterior y nuestro vasto mundo interior, el lenguaje informático tiene topes demostrables teóricamente a partir del conocimiento de su gramática. Existen problemas esencialmente inmanejables para las computadoras, en términos de tiempo y recursos de hardware, como los llamados "problemas NP completos", o incluso 
totalmente refractarios a ser formulados algorítmicamente, como los llamados "problemas indecidibles". Por ejemplo, está demostrado teóricamente que no se puede escribir un algoritmo que, analizando el código de un programa, determine si este se detendrá al ejecutarse. Lanier cree, en ese sentido, que incluso la inteligencia artificial es una "fantasía" que oculta las deficiencias de una "ingeniería chapucera" $(2018,135)$. Además, conocer la naturaleza determinista de todo programa informático nos revela su incapacidad de representar por medio de datos nuestra intimidad psíquica, rica en matices y espontaneidad, así como la realidad extramental, que es, al menos fenoménicamente, altamente aleatoria. Aun cuando el uso del software libre no deja de priorizar el pensamiento que calcula por sobre el pensamiento que reflexiona, la visibilidad del código permite tomar conciencia de los límites de la cuantificación y la velocidad de procesamiento y, de hecho, combatir políticamente su glorificación. De esta forma, permite, en ocasiones, colocar el cálculo al servicio de la teoría y la reflexión.

Así pues, el software manifiesta su carácter farmacológico. Es opresivo e individualista en su versión comercial, que apuntala la estrategia de dominación blanda autoinfligida de la psicopolítica neoliberal, totalizando la transparencia y la predictibilidad basada en datos. Pero, al mismo tiempo, es emancipatorio y comunitario en su versión libre, la cual, en las aplicaciones específicas de navegación anónima por la red, permite resistir a la lógica del panóptico digital y recupera, hasta cierto punto, la dimensión misteriosa, original e irrepresentable de nuestra existencia. Esta dimensión es la que ocupa las profundidades de nuestra psique, y de la cual brotan, carentes de forma o significado, una infinidad de sentimientos, intenciones y estados mentales. Dependiendo de su constitución formal, el software nos deshumaniza, pero humaniza; nos aísla, pero empuja a la cooperación; nos desnuda y al mismo tiempo nos oculta; nos vacía de sentido y al mismo tiempo nos lo devuelve. Si prevalecerá el veneno, el remedio, o ninguno, dependerá de la voluntad de los usuarios, de los seres humanos; aunque a juzgar por la capacidad de adaptación y rebeldía que estos han demostrado a lo largo de la historia, y por la profundidad y complejidad de su existencia, que ninguna tecnología hasta hoy ha podido sujetar plenamente, conviene recordarles a los entusiastas de la libertad-esclavitud psicopolítica, la advertencia del protagonista de 1984 a sus opresores: "Sé que fracasarán. Hay 
algo en el universo - no sé lo que es: algún espíritu, algún principio contra lo que no podrán. (...) El espíritu del Hombre" (Orwell 2000, 276).

\section{Bibliografía}

Han, Byung-Chul, 2014. Psicopolítica. Barcelona: Herder.

Lanier, Jaron, 2018. Ten arguments for deleting your social media accounts right now. New York: Henry Holt and Company.

Lévy, Pierre, 1998. Becoming virtual. New York: Plenum.

Orwell, George, 2000. 1984. Barcelona: Destino.

Roncoroni, Umberto, 2012. Filosofía y software. Lima: Universidad de Lima, Fondo editorial.

Stiegler, Bernard, 2016. "Automatic society, Londres février 2015". Journal of visual art practice 15 (2-3), 192-203.

Zuboff, Shoshana, 2019. The age of surveillance capitalism. New York: Public Affairs. 